\title{
Stereopsis and amblyopia: new treatments for future
}

\section{Mini review}

Amblyopia is defined like an abnormal development of the cerebral cortex as a result of visual impairment occurred during childhood. It is considerate a major cause of vision loss in infants and young children. ${ }^{1}$ Over the past two decades new ways for treating amblyopia are being developed including treatment beyond the critical period. Patching therapy has been used to treat amblyopia for hundreds of years even though its shortcomings are many: poor compliance due to social and psychological factors and vision with one eye worsens their balance and mobility. ${ }^{2,3}$

On the other hand, impaired stereoscopic depth perception is the most common deficit associated with amblyopia. ${ }^{4}$ Stereo-deficient's have a substantial impact on visuomotor tasks, difficulties in playing sports were they are children and locomoting safely in old age. It is known that they may also have limit career options stereopsis is more impacted in strabismic than in anisometropic amblyopia. ${ }^{5}$ Amblyopic eye treatments through the opposite eye penalties have been designed to develop and improve visual acuity in the amblyopic eye regardless of binocular vision. Binocularity is one of the defining features of amblyopia; however amblyopia therapies have only recently included it.

New therapies have been described that directly targets binocular function and improve both monocular and binocular vision in adults and children with amblyopia. ${ }^{6}$ A number of hybrid-binocular approaches have been suggested, which are all directed to recovering monocular function but under binocular viewing. To involve the fixing eye in recovery of vision through intensive training/detection of targets presented to the amblyopic eye, the contrast of the signal in the opposite eye is reduced to a point (determined individually) where binocular combination is achievable. Over time, the treatment strengthens and extends the contrast range over which binocular fusion can occur until it includes images of the same contrast in each eye (like happens in natural viewing). There are no circumstances under which the treatment becomes monocular because without binocular combination, the visual tasks used for treatment are impossible.

Dichoptic training employs simultaneous and separate stimulation of both eyes, were the contrast for the good eye is reduced but not completely obscure vision. In contrast to monocular patching, binocular vision is trained by video games that can only be solve binocularly. ${ }^{7}$ Stereoscope, iPad, video google are different displays used in the new treatment of amblyopia. Diffusion filters using silica particles can reduce the visual acuity without hindering the vision completely. These filters should be useful for strabismic and/ or anisometropic amblyopia to improve visual acuity and binocular vision. $^{8}$

Recently, new virtual reality simulators are allowing through dichoptic training games improve stereopsis in adults who were stereo blind or stereo-deficient owing to strabismus and/or amblyopia. The task was to squash a virtual dichoptic bug on a slanted surface. Following training most participants showed greater stereo-acuity and less suppression. ${ }^{9}$ Finally, non-invasive brain stimulation is another emerging field for patients with amblyopia. A number of established techniques as trans-cranial magnetic stimulation, ${ }^{10}$ and trans-cranial
Volume 5 Issue 2 - 2016

\author{
Antonio Moreno Valladares \\ University Hospital of Albacete, Spain \\ Correspondence: Antonio Moreno Valladares, Glaucoma \\ surgeon, University Hospital of Albacete, Spain, \\ Tel +34 625470822, Email morenovalladares@oftalmancha.com \\ Received: August 10, 2016 | Published: November 01, 2016
}

direct current stimulation ${ }^{11}$ are coining new concepts such as metaplasticity.

\section{Conclusion}

Numerous studies demonstrating that fusing the two eyes information can promote binocular function and reestablishes binocular vision. These advances have raised a number of questions that will provide new insights about plasticity in the visual cortex and amblyopia. New technologies, such as virtual reality, will allow shortterm development of new strategies for the diagnosis and treatment of amblyopia.

\section{Acknowledgments}

None.

\section{Conflicts of interest}

Author declares that there is no conflict of interest.

\section{References}

1. Levi DM, Knill DC, Bavelier D. Stereopsis and amblyopia: A minireview. Vision Res. 2015;114:17-30.

2. Webber AL, Wood JM, Gole GA, et al. Effect of amblyopia on selfesteem in children. Optom Vis Sci. 2008;85(11):1074-1081.

3. Searle A, Norman P, Harrad R, et al. Psychosocial and clinical determinants of compliance with occlusion therapy for amblyopic children. Eye (Lond). 2002;16(2):150-155.

4. Webber AL, Wood J. Amblyopia: Prevalence, natural history, functional effects and treatment. Clin Exp Optom. 2005;88(6):365-375.

5. McKee SP, Levi DM, Movshon JA. The pattern of visual deficits in amblyopia. $J$ Vis. 2003;3(5):380-405.

6. Hess RF, Thompson B. Amblyopia and the binocular approach to its therapy. Vision Res. 2015;114:4-16.

7. Bach M. Dichoptic training for amblyopia. Ophthalmologe. 2016;113(4):304-308.

8. Sasaki M, Iwasaki T, Kondo H, et al. Properties of new diffusion filters for treatment of amblyopia with accurate occlusive effects. Graefes Arch Clin Exp Ophthalmol. 2016;254(6):1181-1187. 
9. Vedamurthy I, Knill DC, Huang SJ, et al. Recovering stereo vision by squashing virtual bugs in a virtual reality environment. Philos Trans $R$ Soc Lond B Biol Sci. 2016;371(1697):20150264.

10. Barker AT, Jalinous R, Freeston IL. Non-invasive magnetic stimulation of human motor cortex. Lancet. 1985;1(8437):1106-1107.
11. Nitsche MA, Paulus W. Excitability changes induced in the human motor cortex by weak transcranial direct current stimulation. J Physiol. 2000;527(Pt 3):633-639. 